\title{
Students' Cognition and Attitude in Writing Descriptive Text
}

\author{
Indah Sari ${ }^{1}$, Anni Holila Pulungan ${ }^{2}$, Rahmad Husein ${ }^{3}$ \\ 1,2,3Postgraduate School, Universitas Negeri Medan, Indonesia \\ Email: indah.sari877@gmail.com
}

\begin{abstract}
College students are in formal operational in period of cognitive development which they can use symbols logically related to abstract concepts, acquire flexibility in thinking as well as the capacities for abstract thinking and mental hypothesis and consider possible alternatives reasoning and problem solving. However, the students' writings have some mistakes in terms of using surface features such as spelling, grammar, usage, punctuation, grammar, vocabulary and tenses. This study aimed to analyze about the students' cognition and attitude in writing descriptive text. The design of this study was descriptive qualitative by conducting the in-depth interview and questionnaire administration. The data of this study were the sentences in descriptive text and transcript of interview. Moreover, the data source were 2 students of $7^{\text {th }}$ semester at STBA - PIA Medan. The results showed that 1) the dominant type of students' attitude in writing descriptive text was cognitive domain followed by affective and conative domains which could be interpreted that the students had positive attitude regarding to the writing of descriptive text, 2) the students' cognition in writing descriptive text was having the stages of writing process which consists of pre-writing, drafting, revising, editing and publishing, and 3) the reasons of applying the students' cognition and attitude in descriptive text were they had the goals and purposes in their thoughts when they were writing. Moreover, they believed that writing could improve their skills in learning English as a foreign language.
\end{abstract}

Keywords: cognition; attitude; writing; descriptive text

\section{Introduction}

In learning process underlies the cognitive process in human brain that perceive by memory, visual imagery and problem solving. In terms of language learning, the process of foreign language learning is usually influenced by many factors which the impact of variables covers a wide scale of various mental processes and other factors (Munkova et al, 2012). Furthermore, these factors influence the quality of foreign language learning such as automatisation, fixation, and anchoring in language structures and cultural specifications, which are then reflected in the fluency, productivity, flexibility and the natural sound of foreign language communication. It is a way how a person (or a group of people) can perceive and process information about uncertain stimuli and situations, or about situations that are considered uncertain or unexpected and this ability can be considered as a precondition for a successful handling of a situation. In essence the process of learning interaction is a process of communication between teachers and students. Through the communication process the teacher can convey their knowledge or experience for students to learn. (Rangkuti, 2019).

Moreover, Bar - Tal (1999) figured out that cognitive structuring as an activity, a process which helps to achieve a certainty by filtering inadequate information, and claimed that when a person processes information gradually, the information is assimilated in a cognitive structure and can be used subsequently. Cognitive process is very important in language learning such as reading and writing of other foreign language that predicts people from being able to communicate with others of a foreign language. On the other hand, Husseina et al (2009) found that learning a new language and being able to communicate in that of a new language is a new scope in human lives and a merit that will live with him throughout our whole life. 
On the hand, one of the important factors in language learning is attitude since it is the leading predictors of success in learning English (Gömleksiz, 2010). Furthermore, Karahan (2007) claims that "positive language attitudes let learner has positive orientation towards learning English. Moreover, Rahimi, \& Hassani (2011) found that students' attitude towards their EFL material and its role will lead them to be successful in learning English as a foreign language. Besides that, Afshari et al, (2013) showed that studying students' attitudes can help others to answer some questions relating to acceptance and usage of technology in teaching and learning. Therefore, it might be said that L2 writing might become a challenge for students if teachers carefully consider their students' personality, their learning styles, social, cultural and cognitive factors and appropriate teaching methods/strategies.

Hence, the most effective strategy is to promote writing as often as possible, together with thinking and conscious reflection on it. Klimova (2013) suggested that students must be provided with feedback on what they have written in order to realize the errors they have made because without sufficient and relevant feedback students are not able to improve both their writing and language skills. On the other hand, one of the reasons why writing is not easy to learn must certainly be cultural differences in the way academic register is perceived and understood in different countries. Then, Zhang and Hyland (2018) found that the student engagement with feedback is a key construct in L2 writing research that merits more attention which the source of the feedback and individual learner factors can shape the process of writing. Therefore, language proficiency and knowledge of learning strategies can play a pivotal role, not only in helping students to understand and interpret feedback, but also in evaluating and monitoring the revision process.

Furthermore, Frear and Bitchener (2015) believed that certain task affected the writers' cognitive burden and it would have the effect on their ability to produce attention-demanding elements in a written text. Moreover, Olive and Kellogg (2002) showed that factors related the writers' skills and to the writing situation differently affect the cognitive effort of text writing. On the other hand, the previous observation and the preliminary data showed that the students' writings had some mistakes in using surface features such as spelling, grammar, usage, punctuation, grammar, vocabulary and tenses. Moreover, preliminary interview indicated that the students felt difficulties and discouraged when they were asked to write or describe something. In line with the phenomena, therefore, this study was analyzed the students' cognition and attitude in writing descriptive texts in terms of investigating the cognitive process and attitude during the writing process in English learning as a foreign language.

\section{Review of Literatures}

\subsection{Nature of Cognition}

Cognition can be defined as conscious mental activities, activities of thinking, understanding, and remembering. Moreover, cognition or mental activity describes the acquisition, storage, transformation, and use of knowledge (Matlin, 2009). Furthermore, it operates every time the people acquire some information, place it in storage, transform that information, and use it and it includes a wide range of mental processes as well. The cognition can be synonymous with the terms cognitive process or cognitive psychology.

Furthermore, in relation to the cognition, there are four major periods or stages in cognitive development as in Piaget's theory (Ginsburg \& Opper, 2016) namely:

1 Sensorimotor (birth to 2 years)

2 Preoperational (2 years to 7 years) 
3 Concrete operational ( 7 years to 11 years)

4 Formal operational (11 years and above)

Therefore, it can be concluded that the human's ability to write systematically can be seen when he is in the formal operational stage since he has the abstract concept or thinking in his mind and describe the things in written language. Moreover, Matlin (2009) explained that there are two reasons of learning about cognition namely: 1) it occupies a major portion of human psychology that almost everything people have done in the past hour required them to perceive, remember, use language, or think, and 2) the cognitive approach has widespread influence on other areas of psychology, such as clinical psychology, educational psychology, and social psychology, for example one cognitive task asks people to recall a specific memory from their past. Furthermore, Wegener and Carlston (2005) described that cognition or connective process is any process that stores knowledge structures in memory or that operates on stored knowledge structures. In addition, there are six cognitive processes, they are: 1) attention, 2) perception 3) memory, 4) language, 5) learning and, 6) higher reasoning/problem solving.

\subsection{Measuring the Human Cognition}

Think- aloud interview procedures proper are used to measure problem- solving processes in working memory in particular, problem solving that is novel and dynamic, involving the manipulation and transformation of information (Leighton, 2017). Moreover, Someren, et al (1994) state that protocol analysis is not only used for the scientific study of cognitive processes, but also for the construction of knowledge-based systems. The think aloud method is a good way to avoid 'false' information and obtain direct data about the solution process that takes place when an expert solves a problem. Furthermore, thinking aloud during problem-solving means that the subject keeps on talking, speaks out loud whatever thoughts come to mind, while performing the task at hand.

Furthermore, Someren, et al, (1994) explain that the think aloud method makes it easy for the subjects, because they are allowed to use their own language. the think aloud method for two reasons:

a. The think aloud method avoids interpretation by the subject and only assumes a very simple verbalization process.

b. The think aloud method treats the verbal protocols that are accessible to anyone, as data thus creating an objective method.

\subsection{The Nature of Attitude}

Attitude means the way people think and feel about someone or something; a feeling or way of thinking that affects a person's behavior or a way of thinking and behaving that people regard as unfriendly, rude, etc. Moreover, an attitude is a disposition to respond favorably or unfavorably to an object, person, institution, or event (Ajzen, 2005). Moreover, Allport (1954) categorized the types attitude which can be described as follow:

1. Cognitive Responses

2. Affective Responses

3. Conative Responses

In conclusion, an individual's favorable or unfavorable attitude toward an object, institution, or event can be inferred from verbal or nonverbal responses toward object, institution, or event in question. These responses can be cognitive nature, reflecting perceptions of the object, or beliefs concerning its likely characteristics; they can be of an affective nature, 
reflecting the person's evaluations and feelings; and they can be of a conative nature, indicating how a person does or would act with respect to the object.

\subsection{Writing}

Writing can be defined as the act, process or activity of one who write something. In term of writing, Vygotsky (1978) stated that the child, given the necessary materials, will gradually pass through the various stages in the development of writing, spontaneously making scribbles, then organized drawings, depicting objects with pictograms, using letter-like shapes to denote words and then words with invented spelling.

In process writing, students experience five interrelated phases: prewriting, drafting, revising, editing, and publishing. Furthermore, Greetham (2001) described the reasons for writing essays namely 1) It forces people to organize the thinking and develop the ideas on the issues, 2) it also provides the writer with the opportunity to get feedback from the others, and 3) it provides a revision of material whether the writer has planned the essay well. following:

Moreover, Mclean (2012) described about the stages of the writing process as the 1. Pre-writing

Prewriting techniques can be helpful in all stages of the writing process, the steps of pre-writing can be seen as follow:
a. Choosing a Topic
b. Using Experience and Observations
c. Reading
d. Freewriting
e. Asking Questions
f. Brainstorming
g. Idea Mapping
h. Searching the Internet
i. Writing an Outline

2. Drafting

Drafting is the stage of the writing process in which the writer develops a complete first version of a piece of writing, and the steps of drafting can be seen as follow:
a. Writing a title
b. Beginning writing with the part writer knows the most about
c. Writing one paragraph at a time and then stop
d. Taking short breaks to refresh the mind
e. Being reasonable with the goals
f. Writing a first draft should include the following elements:
1) An introduction.
2) thesis statement
3) A topic sentence in each.
4) Supporting sentences in each paragraph
5) A conclusion.

3. Revising

Revising is the process when the writer revises, takes a second look at the ideas and the steps of revising can be seen as follow:

a. Creating Unity 

b. Creating coherence
c. Identifying Wordiness
d. Choosing Specific, Appropriate Words
e. Completing a Peer Review

\section{Editing}

Editing is the process when the writer edits, takes a second look at how he expressed his ideas and the steps of editing can be seen as follow:

a. Examining the surface features of the text.

b. Examining the spelling, grammar, usage, and punctuation.

c. Examining the proper format.

\section{Publishing}

Publishing is the process when the writer submits or presents the essay in order to read by someone else. The simple step of publishing is turning in a paper to the teacher.

\subsection{Descriptive Text}

Descriptive text can be defined as a text which gives information about something or someone looks, sounds, etc. Writers use description in writing to make sure that their audience is fully immersed in the words on the page (McLean, 2012). Moreover, McLean (2012) explained that description essays typically describe a person, a place, or an object using sensory details. The structure of a descriptive essay is more flexible than in some of the other rhetorical modes. On the other hand, description essays should describe something vividly to the reader using strong sensory details which appeal to the five human senses: sight, sound, smell, taste, and touch. Then, a description essay should start with the writer's main impression of a person, a place, or an object, and use spatial order to organize the descriptive writing. For example, when a student looks at the picture on the paper and he is asked by the teacher to describe it by words, then, he will analyze it carefully and try to choose the topic and the title for the text. If it is about the human, he will describe it by the appearance of the human, the profession, or the activity relates to the surrounding.

\subsection{The Reasons of Using Cognitive Process in Writing} following:

Flower and Hayes (1981) described about the cognitive process related to the writing as the

1. The process of writing is best understood as a set of distinctive thinking processes which writers orchestrate or organize during the act of composing.

2. These processes have a hierarchical, highly embedded organization in which any given process can be embedded within any other.

3. The act of composing itself is a goal-directed thinking process, guided by the writer's own growing network of goals.

4. Writers create their own goals in two key ways: by generating both high-level goals and supporting sub-goals which embody the writer's developing sense of purpose, and then, at times, by changing major goals or even establishing entirely new ones based on what has been learned in the act of writing.

\section{Research Methods}

This study applied the descriptive qualitative which it is concerned with developing explanations of social phenomena. The data of this study were the sentences in descriptive texts. Moreover, the sources of the data in this study were 12 students at $7^{\text {th }}$ semester students of STBA 
- PIA. They were chosen as the data source regarded as they have the writing subjects in the syllabus such as writing 1 , writing 2 , writing 3 and writing 4 . This study used in depth interview and questionnaire as the technique of collecting data. The technique of analyzing the data by of this study were 1) think aloud protocol for measuring students' cognition, and 2) Likert Scale for measuring the questionnaire. Moreover, Ajzen (2005) classified the steps of measuring students' cognition by using think aloud protocols such as: setting, instructions, warming up, behavior of the experimenter and prompting, recording, transcription of the protocol, and review. Furthermore, Likert scales (1932) can measure other variations of questionnaire such as frequency, quality, importance, and likelihood, etc.

\section{Discussion}

\subsection{Cognitive Process}

Allport (1954) classified the attitude into three types namely: 1) cognitive, 2) affective, and 3) conative. The example of data can be seen as follow:

Data 1 (Respondent 1):

I believe that writing helps me learn

The data 1 showed that the respondent reflected her perceptions of and thought about, the attitude object by expressions of beliefs that link the object to certain characteristics or attributes and responded with strongly agree to the statement.

Furthermore, the total scores of students' answers from the questionnaire showed that the dominantly domain occurred was cognitive (235) followed by affective (230), and conative (225). The data showed that they students mostly responded with agree position which it could be interpreted that they were in positive attitude in writing descriptive text. Moreover, it meant that the students had positive mental, potential action and psychological tendency through experiences which expressed by evaluating a particular favorable object especially in writing descriptive text.

\subsection{The Process of Students' Cognition and Attitude in Writing Descriptive Text}

Mclean (2012) described about the stages of the writing process such as 1) pre-writing, 2) drafting, 3) revising, 4) editing, and 5) publishing. The examples of data from the interview between the interviewer (I) and the respondent (R) can be seen as the following:

1. Prewriting

Data 4 (Respondent 1)

I $\quad$ : What do you before you start writing regarding to the pictures?

RSN : Before I start writing for the first and the second picture, I look at the pictures first and I'm trying to understand the pictures.

2. Drafting

Data 7 (Respondent 1)

I : What do you after you look at the pictures?

RSN : The next step is to choose the right title to this picture which suitable for this condition.

I : After that?

RSN : I start writing for the general one that what people think of and then make the more specific about the condition happen in where directly the person of two elementary student cross the river that happen in Maluku. The next one is to persuade the reader to make they are interested in. 
The data 7 showed that after she observed the pictures then she chose the appropriate title and then she started the writing from the general idea to the specific and decided the goal of the writing that was to persuade the reader. This was the drafting process in which she developed a complete first version of a piece of writing.

3. Revising

Data 10 (Respondent 1)

I : What do you after you write?

RsN : Sometimes, I think I choose this one and after write again, and if it is not suitable I think again and choose the suitable word which suitable with the title.

The data 10 showed that after she wrote her writing and then she thought again and chose the suitable word which related to the title. When she felt the word was not appropriate then she changed the unsuitable word with another one.

4. Editing

Data 13 (Respondent 1)

I : What do you before you revise your writing?

RsN $\quad:$ I check the whole story, the relation between one paragraph to another paragraph and the sentence structure of the text.

The data 13 showed that after she revised her writing and then she checked the relation between one paragraph or the coherence and also the sentence structure as the process of editing.

5. Publishing

Data 16 (Respondent 1)

I : What do you After you finish the writing?

RsN : share it or submit it to the lecturer.

The data 16 showed that after the respondent felt the writing was ready then she submitted it to the lecturer as the process of publishing. Furthermore, from the data analysis it can be classified the students' cognition in writing process stages as the following table:

Table 1. Students' Cognition in Writing Descriptive Text

\begin{tabular}{|c|c|c|}
\hline No & The Stages of Wnting Process & Answers \\
\hline 1. & $\begin{array}{l}\text { Pre - writing } \\
\text { Observe the pictures } \\
\text { Ask Questions } \\
\text { Generate the idea }\end{array}$ & $\begin{array}{l}\text { Yes } \\
\text { Yes } \\
\text { Yes }\end{array}$ \\
\hline 2. & $\begin{array}{l}\text { Drafting } \\
\text { Write a title } \\
\text { Begin writing } \\
\text { Setting goals in the draft } \\
\text { Write an introduction } \\
\text { Write topic sentence } \\
\text { Write supporting sentences } \\
\text { Write a conclusion }\end{array}$ & $\begin{array}{l}\text { Yes } \\
\text { Yes } \\
\text { Yes } \\
\text { Yes } \\
\text { Yes } \\
\text { Yes } \\
\text { Yes }\end{array}$ \\
\hline 3. & $\begin{array}{l}\text { Revising } \\
\text { Identify wordiness } \\
\text { Choose specific, appropnate words }\end{array}$ & $\begin{array}{l}\text { Yes } \\
\text { Yes }\end{array}$ \\
\hline 4. & $\begin{array}{l}\text { Editing } \\
\text { Examine grammar } \\
\text { and Sentence Structure }\end{array}$ & $\begin{array}{l}\text { Usually } \\
\text { Usually }\end{array}$ \\
\hline 5 & $\begin{array}{l}\text { Publishing } \\
\text { Submit the essay }\end{array}$ & Yes \\
\hline
\end{tabular}


The results in the table figured out that the students' cognition in writing descriptive text is having the stages of writing process which consists of pre-writing, drafting, revising, editing and publishing, and 3) the reasons of applying the students' cognition and attitude in writing descriptive text are they have the goals and purposes in their thoughts when they are writing and convey their intention. Moreover, they believe that writing can improve their skills in learning English as a foreign language.

\subsection{The Reasons of Applying Cognitive Process in Writing}

Flower and Hayes (1981) described about the reasons of applying cognitive process related to the writing such as the process of writing is best understood as a set of distinctive thinking processes which writers orchestrate or organize during the act of composing. Moreover, these processes have a hierarchical, highly embedded organization in which any given process can be embedded within any other, the act of composing itself is a goal-directed thinking process, guided by the writer's own growing network of goals. Then, they create their own goals in two key ways: by generating both high-level goals and supporting sub-goals which embody the writer's developing sense of purpose, and then, at times, by changing major goals or even establishing entirely new ones based on what has been learned in the act of writing. The data related to the reason can be seen as the following:

\section{Data 20 (Respondent 1)}

I : What is your goal in writing which is related to the pictures?

RsN : To persuade the reader to make they are interested in, and they want to do something about this.

Data 20 showed that the respondent created the goal of her writing namely to persuade the readers and made them get interested in her descriptive text. Moreover, it was the act of composing itself is a goal-directed thinking process, guided by the writer's own growing network of goals.

Moreover, the findings have the relation to the cognition that according to Piaget's theory (Ginsburg \& Opper, 2016) there are four stages of development namely: 1) sensorimotor (birth to 2 years), 2) preoperational (2 years to 7 years), 3) concrete operational (7 years to 11 years), and 4) formal operational (11 years and above). Since the students were in the formal operational stages, therefore, they could develop their cognitive process or cognition in writing a descriptive text. Moreover, they also had positive attitude in every component such as cognitive, affective and conative domains.

Furthermore, the findings are also supported by Jabali (2018) who found that students had positive attitudes toward writing although they had different backgrounds, learning methodologies, levels of language skills, insights, attitudes and conceptions about writing skill. Furthermore, Olive and Kellogg (2002) also showed that factors related the writers' skills and to the writing situation differently affect the cognitive effort of text writing. It can be concluded that the cognitive process and attitude are important factors in writing especially in descriptive texts.

\section{Conclusion}

It can be drawn the conclusions that:

1. The dominant type of students' attitude in writing descriptive text is cognitive domain followed by affective and conative domains which can be interpreted that the students have positive attitude regarding to the writing of descriptive text. 
2. The students' cognition in writing descriptive text is having the stages of writing process which consists of pre-writing, drafting, revising, editing and publishing.

3. The reasons of applying the students' cognition and attitude in writing descriptive text are they have the goals and purposes in their thoughts when they are writing and convey their intention. Moreover, they believe that writing can improve their skills in learning English as a foreign language.

\section{References}

Afshari, M., Ghavifekr, S ., Siraj, S .,\& Jing, D. 2013. Students' Attitudes towards ComputerAssisted Language Learning. Procedia - Social and Behavioral Sciences 103 pp. $852-859$. Elsevier Ltd

Ajzen, I. 2005. Attitude, Personality and Behavior Second Edition. New York: Open University Press

Allport, G.W. 1954. The Historical Background of Modern Social Psychology. In Lindsey,G (ed) Handbook of Social Psychology, vol.1, Theory and Method. Cambridge, MA: Addisson-Wesley, 3-56

Bar-Tal, Y. \& Spitzer, A. (1999). The Need and Ability to Achieve Cognitive Structuring: Individual Differences That Moderate the Effect of Stress on Information Processing. Journal of Personality and Social Psychology. Vol. 77, No. 1, pp. 33-51

Frear, M.W., \& Bitchener, J. 2015. The Effect of Cognitive Task Complexity on Writing Complexity. Journal of Second Language Writing

Greetham, B. 2001. How to Write Better Essays. New York: Palgrave

Ginsburg \& Opper, 2016. Piaget's Theory of Intellectual Development Third Edition. USA: e-Book: International Psychotherapy Institute

Gömleksiz, M. N. 2010. An Evaluation of Students' Attitudes Toward English Language Learning in Terms of Several Variables. Procedia Social and Behavioral Sciences 9 (2010) 913-918. Elsevier Ltd

Husseina, G., Demiroka, M. S., \& Uzunboylua, H. 2009. Undergraduate Student's Attitudes towards English Language. Procedia Social and Behavioral Sciences 1 (2009) 431-433. Elsevier Ltd

Jabali, O. 2018. Students' Attitude towards EFL University Writing: A Case Study at An-Najah National University, Palestine. Heliyon. Elsevier Ltd

Karahan, F. 2007. Language Attitudes of Turkish Students towards the English Language and Its Use in Turkish Context. Journal of Arts and Sciences.7, 73-87

Klimova, B. F. 2013. Constraints and Difficulties in The Process of Writing Acquisition. Procedia Social and Behavioral Sciences 122, 433 - 437. Elsevier Ltd

Leighton, J. P. 2017. Using Think-Aloud Interviews and Cognitive Labs in Educational Research. New York. Oxford University Press

Likert, R. (1932). A Technique for the Measurement of Attitudes. Archives of Psychology, 140, 1-55

Flower, L.\& Hayes, J. R. 1981.A Cognitive Process Theory of Writing. College Composition and Communication, Vol. 32, No. 4, pp. 365-387

Matlin, M. W. 2009. Cognition Seventh Edition. Danvers, USA: John Wiley \& Sons, Inc

McLean, S. 2012. Successful Writing. A Creative Common

(http://creativecommons.org/licenses/by-nc-sa/ 3.0/) license

Munková, D., Stranovská, E., \& Duračková, B. 2012. Impact of Cognitive-Individual Variables on Process of Foreign Language Learning. Procedia - Social and Behavioral Sciences 46, 5430 - 5434. Elsevier Ltd

Olive, T., \& Kellogg, R.T. 2002. Concurrent Activation of High-and-Low Level Production Processes in Written Composition 
Peregoy, S. F.,\& Boyle, O. F. 2017. Reading, Writing, and Learning in ESL: A Resource Book for Teaching K-12 English Learners Seventh Edition. New York: Pearson

Polit, D.F. and Beck, C.T. 2017. Nursing Research Generating and Assessing Evidence for Nursing Practice. 10th Edition, Wolters Kluwer

Rangkuti, A. N. and Hasibuan, W. S. (2019). Learning of Spatial Operations in 1st Grade of Junior High School (MTs.S NU Paringgonan) Ulu Barumun Sub-district Padang Lawas Regency. Budapest International Research in Linguistics and Education Sciences (BirLE) Journal, 2(1); 181-193.

Rahimi, M., \& Hassani, M. 2011. Attitude towards EFL Textbooks as a Predictor of Attitude towards Learning English as a Foreign Language. Procedia - Social and Behavioral Sciences 31 (2012) 66 - 72. Elsevier Ltd

Sternberg, R J., \& Sternberg, K. 2012. Cognitive Psychology, Sixth Edition. California, USA: Wadsworth Cengage Learning

Someren, M. W. V., Barnard, Y. F., \& Sandberg, J. A.C. 1994. The Think Aloud Method: A Practical Guide to Modelling Cognitive Processes. London: Academic Press

Vygotsky, L.S. 1978. Mind in Society: The Development of Higher Psychological Processes. Cambridge, Massachusetts. Harvard University Press

Wegener, D.T.,\& Carlston .2005. Cognitive Processes in Attitude Formation and Change in Book: The Handbook of Attitudes. London: Lawrence Erlbaum Associates Publisher

Zhang, Z.V, \& Hyland, K. 2018. Student engagement with teacher and automated feedback on L2 writing. Assessing Writing $\times x \times(x \times x \times) \times x x-x \times x$ 